\title{
Evaluation of Pre-donation Deferral Reason among the Blood Donors Visiting ESIC Hospital in Eastern India
}

\author{
Pisudde $\mathbf{P M}^{1^{*}}$, Shyam $\mathbf{S}^{2}$, Dutt Rekha ${ }^{1}$ and Soniya Gon ${ }^{2}$ \\ ${ }^{1}$ Department of Community Medicine, ESI-PGIMSR, ESIC Medical College and ESIC hospital, Diamond Harbour road, Joka Kolkata-700104, India \\ ${ }^{2}$ Department of Pathology, ESI-PGIMSR, ESIC Medical College and ESIC hospital, Diamond Harbour road, Joka Kolkata-700104, India
}

"Corresponding author: Pravin Pisudde, Department of Community Medicine, ESI-PGIMSR, ESIC Medical College and ESIC hospital, Diamond Harbour road, Joka Kolkata-700104, India, Tel: 08055473360; E-mail: drpravinpisudde@gmail.com

Received date: Jan 22, 2015, Accepted date: Mar 05, 2015, Publication date: Mar 09, 2015

Copyright: ( $) 2015$ Pisudde PM, et al. This is an open-access article distributed under the terms of the Creative Commons Attribution License, which permits unrestricted use, distribution, and reproduction in any medium, provided the original author and source are credited.

\begin{abstract}
Blood transfusion is an indispensable component of health care. It contributes to saving millions of lives each year in both routine and emergency situations, permits increasingly complex medical and surgical interventions and dramatically improves the life expectancy and quality of life of patients with a variety of acute and chronic conditions. to analyze and evaluate the reasons for donor deferral at ESIC hospital blood bank which has been recently opened up, so that temporarily deferred donors with corrective reasons can be identified, properly informed and guided to improve their quality of blood for future donation. Out of all the donors $1600(90.3 \%)$ were eligible for donation and $171(9.7 \%)$ blood donors were deferred. Temporary deferrals $(77.8 \%)$ were more common than permanent deferral $(22.2 \%)$. The most reasons for deferral in blood donors were Anaemia (40.9\%), Hypertension (52.6\%), Antibiotic therapy $(10.5 \%)$, Previous donation $(5.3 \%)$ and Malaria $(4.5 \%)$. Thus, it is important to evaluate the reasons of whole blood donor deferral to guide the recruitment and retention efforts in newly started blood bank.
\end{abstract}

Keywords: Pre-donation deferral; Blood donation; Eastern India

\section{Introduction}

Blood transfusion is an indispensable component of health care. It contributes to saving millions of lives each year in both routine and emergency situations, permits increasingly complex medical and surgical interventions and dramatically improves the life expectancy and quality of life of patients with a variety of acute and chronic conditions. Patients who require transfusion as part of their clinical management have the right to expect that sufficient blood will be available to meet their needs and to receive the safest blood possible. However, many patients still die or suffer unnecessarily because they do not have access to safe blood transfusion. The timely availability of safe blood and blood products is essential in all health facilities in which transfusion is performed, but in many developing and transitional countries there is a widespread shortfall between blood requirements and blood supplies [1]. As per WHO, minimum need to meet a nation's basic requirement for blood is approximately about $1 \%$ of the population (10 per 1000 population); these requirements are directly proportional to the type of advanced health-care systems in any country [2].

In India, according to NACO's(National AIDS control organization) statistics the annual requirement of blood for the country was estimated at 12 million units, of which DAC(Department of AIDS control) had a target of collecting 55 lakh units through the network of DAC supported blood banks in 2013-2014. The endeavour was to meet the blood needs of the country with voluntary nonremunerated donations, through a well-coordinated Blood Banking Programme. In 2013-2014, a total of 57 lakh units were collected and $84 \%$ of this was through voluntary blood donation [3]. The achievement seems to be nice but still there is huge gap of approximately 60 lakh units as compared to required target set by
WHO. Onto that paucity of healthy, safe blood donors has always been a serious problem for blood banks, across all health sectors in India. Blood donor deferral is an uncomfortable and sad experience for the blood donor as well as the blood bank where screening is done. Moreover, a deferred prospective donor often leaves them with negative feelings about themselves as well as the blood donation process [4]. These blood donors are less likely to return in future for any blood donation and have pronounced effect on them for future donation [5]. In most of the blood banks, focus is more at recruiting new blood donors while retention and re-entry of recruited but deferred due to various causes are ignored. Pre donation donor selection is usually performed for the safety of not only the blood donor but also for the recipient. Monthly statistics sent to the higher authorities exclusively includes transfusion transmitted diseases data and excludes other causes [6]. It is also very important to study and analyze various causes for donor deferral, in order to categorize them under temporary and permanent deferrals and to increase influx of the donors to donate blood without deferral. Hence, the present study was taken to analyze and evaluate the reasons for donor deferral at ESIC hospital blood bank which has been recently opened up, so that temporarily deferred donors with corrective reasons can be identified, properly informed and guided to improve their quality of blood for future donation.

\section{Methodology}

The present cross sectional study was carried out among all whole blood voluntary as well replacement donors who arrived for blood donation in the blood bank of ESIC Hospital, blood bank, Joka, Kolkata. Data was collected from 1st September 2013 to 31st December 2014. Blood bank in ESIC hospital Joka is functional since August 2014. The donors were evaluated on the basis of pre-screening criteria involving questionnaire having person details, clinical details, 
Citation: Pisudde PM, Shyam S, Rekha D, Gon S (2015) Evaluation of Pre-donation Deferral Reason among the Blood Donors Visiting ESIC

Page 2 of 4

physical examination, Haemoglobin $[\mathrm{Hb}]$ estimation, blood pressure and temperature. Haemoglobin estimation is done by automated haematology analyzer [HemoCue $\mathrm{Hb} 201^{+}$]. The West Bengal State AIDS Control Society [WBSACS] guidelines were used for deferral of blood donors. Deferred donors data was analysed using Epi Info 7 with respect to age, sex, type of donor and causes for deferral were categorised into temporary and permanent, based on the curability of the condition.

\section{Results}

During the study period total of 1771 whole blood donors who arrived for blood donation at ESIC hospital blood bank, Joka, 1600 (90.3\%) were eligible for donation and 171 (9.7\%) blood donors were deferred. Female population were found to have higher deferral than the male population ( $41.7 \%$ vs $8.1 \%$ ) (Table 1$)$.

\begin{tabular}{|l|l|l|l|}
\hline & Donors registered & No. of Deferral & Deferral rate (\%) \\
\hline Males & 1687 & 136 & 8.1 \\
\hline Female & 84 & 35 & 41.7 \\
\hline Total & 1771 & 171 & 9.7 \\
\hline
\end{tabular}

Table 1: Deferral Rate of whole blood donors at ESIC hospital blood bank, Joka.

\begin{tabular}{|c|c|c|c|}
\hline & Female (\%) & Male (\%) & Total (\%) \\
\hline \multicolumn{2}{|c|}{ Age Group(years) } & & \\
\hline$<20$ & $1(2.9)$ & $3(2.1)$ & $4(2.3)$ \\
\hline $21-30$ & $9(25.7)$ & $58(42.7)$ & $67(39.2)$ \\
\hline $31-40$ & $14(40.0)$ & $39(28.7)$ & $53(31.0)$ \\
\hline $41-50$ & $6(17.1)$ & $27(19.9)$ & $33(19.3)$ \\
\hline $51-60$ & $5(14.3)$ & $9(6.6)$ & $14(8.2)$ \\
\hline \multicolumn{2}{|l|}{ Blood Group } & & \\
\hline $\mathrm{A}^{+}$ & $14(40.0)$ & $43(31.6)$ & $57(33.3)$ \\
\hline $\mathrm{B}^{+}$ & $12(34.3)$ & $36(26.5)$ & $48(28.1)$ \\
\hline $\mathrm{AB}^{+}$ & $4(11.4)$ & $17(12.5)$ & $21(12.3)$ \\
\hline $\mathrm{O}^{+}$ & $5(14.3)$ & $29(21.3)$ & $34(19.9)$ \\
\hline$A^{-}$ & $0(0)$ & $4(2.9)$ & $4(2.3)$ \\
\hline $\mathrm{B}^{-}$ & $0(0)$ & $2(1.5)$ & $2(1.2)$ \\
\hline$A B^{-}$ & $0(0)$ & $2(1.5)$ & $2(1.2)$ \\
\hline $\mathrm{O}^{-}$ & $0(0)$ & $3(2.2)$ & $3(1.8)$ \\
\hline \multicolumn{2}{|l|}{ Occupation } & & \\
\hline Buisness & $1(2.9)$ & $20(14.7)$ & $21(12.3)$ \\
\hline Farmer & $0(0)$ & $8(5.9)$ & $8(4.7)$ \\
\hline Home maker & $23(65.7)$ & $0(0)$ & 23(13.5) \\
\hline Service & $10(28.6)$ & $102(75.00)$ & 112(65.5) \\
\hline
\end{tabular}

\begin{tabular}{|l|l|l|l|}
\hline Student & $1(2.9)$ & $5(3.7)$ & $6(3.5)$ \\
\hline Unemployed & $0(0)$ & $1(0.7)$ & $1(0.6)$ \\
\hline Total & $35(100)$ & $136(100)$ & $171(100)$ \\
\hline
\end{tabular}

Table 2: Age, sex, blood group, occupation distribution of the deferred subjects.

Above Table 2 shows the distribution of the deferred donors. Deferred donor age group ranged from 18 to 60 years with a mean age of 34.7 years. Deferral rate was highest among 21-30 years age group (39.2\%) followed by $31-40$ years (31\%), $41-50$ years (19.3\%) and 51-60 years $(8.2 \%)$. Above table also shows that majority $40 \%$ females deferred donors were from age group 31-40 years. The distribution of blood group in deferred population was found to be maximum among blood group in $\mathrm{A}^{+} \mathrm{ve}(33.3 \%)$ followed by $\mathrm{B}^{+} \mathrm{ve}(28.1 \%)$ and $\mathrm{O}^{+} \mathrm{ve}$ (19.9\%). Distribution of occupation showed that majority of the deferred donors were service class $(65.5 \%)$ followed by home maker (13.5) who were females followed by business class people(12.3\%).

\begin{tabular}{|l|l|l|l|}
\hline Type of Deferral & Female (\%) & Male (\%) & Total (\%) \\
\hline Permanent & $2(5.7)$ & $36(26.5)$ & $38(22.2)$ \\
\hline Temporary & $33(94.3)$ & $100(73.5)$ & $134(77.8)$ \\
\hline Total & $35(100)$ & $136(100)$ & $171(100)$ \\
\hline
\end{tabular}

Table 3: Frequency of temporary and permanent whole blood donors.

Table 3 shows that distribution of the deferred population as per temporary and permanent deferral. As it can be seen that permanent donor deferral is $22.7 \%$ and temporary donor deferral was $77.8 \%$. It can be seen that permanent deferral is very less in females $(5.7 \% \mathrm{Vs}$ 94.3\%).

\begin{tabular}{|l|l|l|}
\hline $\begin{array}{l}\text { Reasons for Permanent } \\
\text { deferral }\end{array}$ & $\begin{array}{l}\text { No. of permanent deferral } \\
(\%)\end{array}$ & $\begin{array}{l}\% \\
\text { Deferral }\end{array}$ \\
\hline Hypertension & $33(86.8)$ & 19.2 \\
\hline Asthma & $2(5.3)$ & 1.2 \\
\hline Renal Disease & $2(5.3)$ & 1.2 \\
\hline Epilepsy & $1(2.6)$ & 0.6 \\
\hline Total & $38(100.0)$ & 22.2 \\
\hline
\end{tabular}

Table 4: Distribution of permanent deferral donors reasons.

The commonest permanent deferral cause was hypertension (86.8\%) followed by asthma and renal disease constituting $5.3 \%$ of permanent deferred donors. One donor deferred was on epilepsy treatment forming $2.6 \%$ of the permanent deferred donor.

\begin{tabular}{|l|l|l|}
\hline Reasons for Temporary deferral & No. of Deferral (\%) & \% Total Deferral \\
\hline Anaemia & $70(52.6)$ & 40.9 \\
\hline Antibiotic Therapy & $14(10.5)$ & 8.2 \\
\hline Previous donation & $7(5.3)$ & 4.1 \\
\hline Malaria & $6(4.5)$ & 3.4 \\
\hline
\end{tabular}




\begin{tabular}{|l|l|l|}
\hline Hypotension & $5(3.8)$ & 2.9 \\
\hline Jaundice & $5(3.8)$ & 2.9 \\
\hline Dog Bite & $4(3.0)$ & 2.3 \\
\hline Respiratory tract infections(RTI) & $3(2.3)$ & 1.8 \\
\hline Alochol Consumption & $2(1.5)$ & 1.2 \\
\hline Medications & $2(1.5)$ & 1.2 \\
\hline Menstruation & $2(1.5)$ & 1.2 \\
\hline Rare Blood group & $2(1.5)$ & 1.2 \\
\hline Tattoo & $2(1.5)$ & 1.2 \\
\hline Conjunctivitis & $1(0.8)$ & 0.6 \\
\hline Diarrhoea & $1(0.8)$ & 0.6 \\
\hline Fever & $1(0.8)$ & 0.6 \\
\hline Tachycardia & $1(0.8)$ & 0.6 \\
\hline Tooth extraction & $1(0.8)$ & 0.6 \\
\hline Under Weight & $1(0.8)$ & 0.6 \\
\hline Total & $133(100)$ & 77.8 \\
\hline
\end{tabular}

The donor deferral population was categorized into temporary and permanent deferrals for optimizing donor recruitment and retention in the long run. Among the deferrals, temporary causes (77.8\%) were more common as compared to permanent causes (22.2\%). It was seen also in other studies conducted $[6,9-11,14,16,19,20,23,24]$ that deferral due temporary reasons were more than due to permanent reason but study conducted by Girish et al in India it was seen that deferral reason were equally in temporary and permanent reason. This may be due to the fact that study conducted in district transfusion centre Shimoga. In present study permanent deferral is very less in females $(5.7 \%$ Vs 94.3\%) this may be due higher prevalence of anaemia in women which is constituting the major cause of temporary deferral in the study.

The major temporary deferral cause was anemia (52.6\%) in our study which was similar with other previous studies [6-12,15,18,20-25]. As the hospital caters to the insured worker population in industry, high prevalence of anemia could be due to poor nutritional status and ill health. The effect of differences in donor characteristics on low haemoglobin levels should be taken into consideration for donor counseling, recruitment and retention efforts. Information about how to increase the haemoglobin levels should be provided to the donors. For example, food intake with high iron or taking multivitamin containing iron should be encouraged and educate to donate blood at a later date after the cause is rectified. Thus evaluation and management of anemia plays a pivotal role in rural population. Study in Iran by Birjandi et al. [15] stated that medications was the major cause of deferral but in our study it was seen that antibiotic therapy was the second most common cause of temporary deferral. Antibiotic therapy could be due to increased accessibility to the hospital to the insured patients (IP) and availability of free medicines. All the other listed temporary causes in the present study can be treated with appropriate education, counseling and related medications for the cause.

The most common reason for permanent deferral in our study was hypertension $(86.8 \%)$ same was also found in other studies conducted in different parts of world [6,10-12,14-17,20,22,24,25]. The probable reason could be that all donors are insured persons and get regular health checkup done in the ESIC hospital. The other frequent permanent deferral causes were cardiac asthma and renal disease (5.3\%). Most of the insured persons are workers in factories and polluted environment and are exposed to polluted environment and heavy physical work of long duration hence they are prone for asthma and illness.

Donor education about selection and deferral criteria needs to be addressed as on priority basis in the blood banks. Monitoring and evaluation of deferral rates and its reasons could be used as a helpful indicators for increasing the frequency of blood donation in newly formed blood bank such as in ESIC hospital Joka.

\section{Conclusion}

The present study evaluates the donor deferral rate and reasons of donor deferral among the blood bank catering the insured population. Awareness about categorization of donor deferral causes into temporary and permanent deferrals is required for all the blood banks and transfusion services. All the potential donors deferred for temporary reason must be informed during the time of deferral about the reasons and time for blood donation. These donors should be counselled, educated and encouraged to improve the efficiency of donor programme. Also, temporary deferred donors require 
Citation: Pisudde PM, Shyam S, Rekha D, Gon S (2015) Evaluation of Pre-donation Deferral Reason among the Blood Donors Visiting ESIC Hospital in Eastern India. J Blood Disorders Transf 6: 255. doi:10.4172/2155-9864.1000255

Page 4 of 4

appropriate follow up and management so as increase the future donors. Thus, evaluating the profile of blood donors will help to identify target population to increase the pool of voluntary donors. However, health officials should provide necessary essential data from time to time to design and implementation of proper education material to decrease the incidences of common deferral reasons. This health education will also help in increasing the health status of the society.

There is scarcity of literature regarding donor deferral causes among different population. Furthermore studies involving larger population, screening methodologies involving more parameters at local, state and national level are required to improve the quality of blood donation.

\section{Acknowledgement}

We are thankful to Dr Soniya Gon, Incharge and Dr Saha Medical Officer, Blood bank ESIC hospital Joka for their kind support in conducting this study.

\section{References}

1. WHO (2010) $100 \%$ voluntary blood donation: a global framework for action. Switzerland, 123.

2. WHO (2009) Media centre, fact sheets, Blood safety and availability, Facts and figures from the 2007 Blood Safety Survey. Fact sheet N 279.

3. http://www.naco.gov.in/upload/2014\%20mslns/NACO_English \%2020134.pdf.

4. http://www.naco.gov.in/upload/REPORTS/ Annual_Report_NACO_2008-09.pdf.

5. Custer B, Chinn A, Hirschler NV, Busch MP, Murphy EL (2007) The consequences of temporary deferral on future whole blood donation.Transfusion 47: 1514-1523.

6. Bashawri LA (2005) A review of predonation blood donor deferrals in a university hospital. J Family Community Med 12: 79-84.

7. Bahadur S, Jain S, Goel RK, Pahuja S, Jain M (2009) Analysis of blood donor deferral characteristics in Delhi, India. Southeast Asian J Trop Med Public Health 40: 1087-1091.

8. Agnihotri N (2010) Whole blood donor deferral analysis at a center in Western India.Asian J Transfus Sci 4: 116-122.

9. Unnikrishnan B, Rao P, Kumar N, Ganti S, Prasad R, et al. (2011) Profile of blood donors and reasons for deferral in coastal South India.Australas Med J 4: 379-385.
10. Kouao MD, Dembelé B, N'Goran LK, Konaté S, Bloch E, et al. (2012) Reasons for blood donation deferral in sub-Saharan Africa: experience in Ivory Coast.Transfusion 52: 1602-1606.

11. Kulkarni N (2012) Analysis of donor deferral in blood donors. Journal of Evolution of Medical and Dental Sciences 1: 1081-8087.

12. Rehman S, Arif SH, Mehdi G, Mirza S, Saeed N, et al. (2012) Evaluation of blood donor deferral causes: A tertiary care centre based study. J Blood Disorders Transf 3: 131.

13. Girish CJ, Chandrashekhar TN, Ramesh BK, Kanitkar SM (2012) PreDonation Deferral of Whole Blood Donors. Journal of Clinical and Diagnostic Research 6: 47-50.

14. Gonçalez TT, Sabino EC, Schlumpf KS, Wright DJ, Mendrone A, et al. (2013) Analysis of donor deferral at three blood centers in Brazil.Transfusion 53: 531-538.

15. Birjandi F, Gharehbaghian A, Delavari A, Rezaie N, Maghsudlu M (2013) Blood donor deferral pattern in Iran.Arch Iran Med 16: 657-660.

16. Shah SD, Shah MC, Bhatnagar NM, Gajjar MD, Soni SA, et al. (2013) Analysis of blood donor deferral characteristics in a tertiary care hospital in a Blood Bank - A review. SEAJCRR 2: 389-395.

17. http://www.palmonline.org/node/142.

18. Mangwana S (2013) Analysis of blood donor deferral pattern: Scenario in a Tertiary Health Care Hospital in India.Asian J Transfus Sci 7: 160-161.

19. Prados Madrona D, Fernández Herrera MD, Prados Jiménez D, Gómez Giraldo S, Robles Campos R (2014) Women as whole blood donors: offers, donations and deferrals in the province of Huelva, south-western Spain.Blood Transfus 12 Suppl 1: s11-20.

20. Kasraian L, Negarestani N (2015) Rates and reasons for blood donor deferral, Shiraz, Iran. A retrospective study.Sao Paulo Med J 133: 36-42.

21. Vamseedhar A, Nalinimohan C, Lakshmi R, Mrinalini VR, Sivachandran (2014) Evaluation of Pre-donation Deferral Causes in Whole Blood Donor Population at a Tertiary Rural Health Centre. IJSR 3: 668-671.

22. Ekwere TA, Ino-Ekanem M, Motilewa OO, Ibanga IA (2014) Pattern of blood donor deferral in a tertiary hospital, South-south, Nigeria: A threeyear study review. Int J Blood Transfus Immunohematol 4: 7-13.

23. Gajjar H, Shah FR, Shah NR, Shah CK (2014) Whole blood donor deferral analysis at General hospital blood bank-A retrospective study. NHL Journal of Medical Sciences 3: 71-76.

24. Ngoma AM, Goto A, Nollet KE, Sawamura Y, Ohto H, et al. (2014) Blood Donor Deferral among Students in Northern Japan: Challenges Ahead.Transfus Med Hemother 41: 251-256.

25. Patil RS, Mhetre S, Rayate M, Karache AG (2014) Analysis of Blood Donor Deferral causes in Solapur district. Int J Biol Med Res 5: 4227-4230. 